\title{
APROXIMAÇÕES ENTRE EDUCAÇÃO INFANTIL E NEUROCIÊNCIA: Formação Acadêmico-Profissional de Coordenadoras Pedagógicas
}

\author{
Elena Maria Billig Mello ${ }^{1}$ \\ Clotilde Panciera Grazziotin ${ }^{2}$
}

\begin{abstract}
RESUMO
Esta pesquisa descritiva, com abordagem qualitativa, objetivou investigar concepções e estratégias metodológicas das coordenadoras pedagógicas da Educação Infantil de uma rede pública municipal de ensino, para o assessoramento à práxis pedagógica, na perspectiva da Neurociência. Os procedimentos metodológicos envolveram entrevista semiestruturada, com questões relacionadas à prática pedagógica, ao processo ensino-aprendizagem e à Neurociência; e encontros de formação e acompanhamento da prática educativa. Apresenta referencial teórico em Vasconcellos, Freire, Cosenza e Guerra, Lima, Craidy e Kaercher, Oliveira, entre outros autores. Como resultados da pesquisa, temos: maior comprometimento das coordenadoras pedagógicas na formação docente junto aos professores; melhoria no processo ensino-aprendizagem; compreensão da importância da Neurociência aplicada à educação; valorização da formação acadêmico-profissional como possibilidade de crescimento profissional e pessoal; aplicação de metodologias inovadoras nas instituições de Educação Infantil.
\end{abstract}

Palavras-chave: Educação infantil. Formação de docentes. Neurociência. Coordenação pedagógica.

APPROACHES BETWEEN CHILD EDUCATION AND NEUROSCIENCE: ACADEMIC-PROFESSIONAL FORMATION OF PEDAGOGICAL COORDINATORS

\begin{abstract}
This descriptive research, with qualitative approach that objected to investigate conceptions and methodological strategies of pedagogical coordinators of child education of a municipal public net, to the advisory for the pedagogical praxis, in neuroscience's perspective. The methodological procedures involved half structured interview with questions related to the pedagogical practice, to the teaching-learning process and to the Neuroscience; and meetings of formation and educative practice monitoring. Theoretical reference in Vasconcellos, Freire, Cosenza and Guerra, Lima, Craidy e Kaercher, Oliveira, between other authors. As a result of the research we have: greater commitment of the pedagogical coordinators in the teacher training with teachers; improvement of the teaching-learning process; comprehension of the importance of applied Neuroscience to education; valorization of academic-professional training as a possibility of professional and personal growth; implementation of innovated methodologies in child education institutions.
\end{abstract}

Keywords: Child Education. Teacher training. Neuroscience. Pedagogical coordination.

Recebido em: $12 / 9 / 2018$

Aceito em: 21/10/2018

\footnotetext{
${ }_{1}$ Graduação em Letras. Mestrado em Educação e Doutorado em Educação. É professora e pesquisadora. Membro da Associação Nacional de Política e Administração da Educação (Anpae), da Associação Nacional de Pós-Graduação e Pesquisa em Educação (Anped) e da Rede Latino-Americana de Estudos sobre Trabalho Docente (Rede Estrado). É professora-adjunta na Graduação e Pós-Graduação na Universidade Federal do Pampa - Unipampa. Líder do Grupo de Pesquisa em Inovação Pedagógica na Formação Acadêmico-Profissional de Profissionais da Educação (Grupi). Tem experiência na área de educação, com ênfase nos seguintes temas: valorização e formação de professores, formação acadêmico-profissional, inovação pedagógica, pedagogia universitária, política educacional, gestão da educação. http://lattes. cnpq.br/7336897624367746. https://orcid.org/0000-0003-0366-3021. profelena@gmail.com

2 Graduação em Pedagogia - Habilitação em Educação Infantil pela Pontifícia Universidade Católica do Rio Grande do Sul (2002). Especialização em docência em Libras pela Universidade Tuiuti do Paraná (2008), em Ensino e Aprendizagem de Matemática na Educação Infantil e no Ensino Fundamental I pela Universidade Católica de Brasília (2012) e em Neurociência Aplicada à Educação pela Universidade Federal do Pampa (2017). Professora orientadora pedagógica e professora regente na Escola Municipal de Educação Infantil Cecília Meireles. Graduação em Medicina Veterinária pela Pontifícia Universidade Católica do Rio Grande do Sul (1992). http://lattes.cnpq. br/7087585602089106. https://orcid.org/0000-0002-4039-6789. clopancierag@gmail.com
} 
Por muito tempo predominou na educação das crianças pequenas um modelo assistencialista com enfoque no cuidar, sem enxergá-las como potentes para aprender dentro de suas subjetividades, minimizando as oportunidades de experiências. Machado (2010, p. 26) observa que "menosprezar a capacidade de elaboração subjetiva de cada ser humano ou a responsabilidade da instituição de Educação Infantil frente à gama de conhecimentos que serão colocados à disposição das crianças significa, no mínimo, empobrecer o universo infantil". A historicidade da Educação Infantil perpassa os séculos e acompanha a cultura de cada época, designando os cuidados e a atenção à infância de acordo com as concepções e modos de vida organizados em cada momento histórico. Os cuidados com as crianças sempre existiram, porém eram entendidos como responsabilidade apenas das famílias, todavia, conforme a sociedade se organizava de acordo com necessidades emergidas, outras formas de atendimento a essas crianças foram surgindo.

A infância possui registros históricos bastante tardios, o que aponta para a pouca importância atribuída a essa fase da vida no passado. Em alguns momentos históricos, a infância foi entendida apenas como um período transitório para a vida adulta e as crianças eram tratadas de igual forma, sem distinção pela sua idade, misturavam-se aos adultos rotineiramente, frequentavam os mesmos locais, vestiam-se como pequenos adultos. A infância, como é entendida atualmente, até o século 16 inexistia (ARIÉS, 1978). Nascimento, Brancher e Oliveira (2008, p. 6) complementa que: "A vida era igual para todas as idades, ou seja, não havia muitos estágios e os que existiam não o eram tão claramente demarcados" e "isto não significa negar a existência biológica destes indivíduos. Significa, em realidade, reconhecer que antes do século XVI, a consciência social não admite a existência autônoma da infância como uma categoria diferenciada do gênero humano" (Ibidem).

As escolas infantis surgem entre os séculos 16 e 17 junto com o pensamento pedagógico moderno e com ideias criadas pelos movimentos religiosos existentes na época (OLIVEIRA, 2010). Muitos teóricos dedicaram-se a estudar a infância, influenciando a educação na sua época e deixando um legado para as próximas gerações. Entre eles encontra-se Comenius (1592 -1670) que, de acordo com Oliveira (Ibidem, p. 11), afirmava "que o processo de aprendizagem se iniciava pelos sentidos. Impressões sensoriais advindas da experiência com manuseio de objetos seriam internalizadas e futuramente interpretadas pela razão".

Ainda durante o século 18, opondo-se às formas disciplinadoras que utilizavam punições físicas, castigos e premissas religiosas de controle e autoritarismo, aparece como referência o filósofo Jean-Jacques Rousseau (1712-1778), alterando radicalmente as formas de pensar e ver a infância, colocando a criança no centro de sua teoria; considerado o pai da Pedagogia moderna, que

(...) produziu uma teorização pedagógica cada vez mais atenta para o valor da infância, para a função antropológica que esta veio a exercer (de renovação do homem, reconduzindo-o para formas mais espontâneas, mais livres, mais originárias), para o papel dialético que ela deve exercer na sociedade do futuro (que deve libertar e não comprimir a infância) (CAMBI, 1999, p. 387). 
Complementamos com as ideias de Oliveira (2010, p. 12) de que Rousseau acreditava que as crianças pequenas deveriam "experimentar desde cedo coisas e situações de acordo com seu próprio ritmo, com seu processo maturacional". Tanto nos estudos de Comenius como nos de Rousseau aparecem aspectos relacionados à Neurociência, quando levam em conta a educação pelos sentidos, o desenvolvimento/crescimento, a cognição, as especificidades etárias, e que com seus achados prestaram contribuições à educação.

Segundo Cambi (1999), no século 19 a preocupação com a infância torna-se presente na sociedade e passa a ser concebida como uma etapa a ser tratada diferente da dos adultos, merecendo atenção específica às suas características. As ciências humanas e as instituições educativas burguesas puseram a criança no centro da Pedagogia, assumida na sua especificidade psicológica e na sua função social. "A infância foi vista como uma idade radicalmente diferente em relação à adulta, submetida a um processo evolutivo complexo e conflituoso, emotivo e cognitivo, portadora de valores próprios e exemplares: da fantasia, à igualdade, à comunicação" (Ibidem, p. 387).

Em meio a essas mudanças e com a institucionalização da escola, inicia-se uma nova forma de olhar esses sujeitos e da busca, cada vez mais frequente, em saber e entender onde e como situam-se as crianças nesse novo contexto. A infância passa a ter visibilidade, invade as agendas políticas, causa preocupação e envolvimento social. O século 20 mobilizou as Ciências Sociais e Humanas a estudar, a conhecer a criança na sua essência, na sua complexidade e finalmente enxergá-la como sujeito de direitos, ativa, capaz e que está inserida na cultura local e global.

No Brasil, a partir de lutas protagonizadas por movimentos sociais pela democratização da educação pública, é reconhecida na Constituição de 1988 a educação em creches e pré-escolas como um direito da criança e dever do Estado (OLIVEIRA, 2010). É nesse contexto de reflexões, discussões e mudanças com a organização da sociedade e de suas demandas que se encontra a Educação Infantil atualmente, em que instituições de ensino, movimentos sociais, educadores e órgãos governamentais se articulam pensando em políticas públicas que priorizem o atendimento das crianças em espaços coletivos, atentos às necessidades e especificidades dessa etapa.

Somos cientes da importância da Lei de Diretrizes e Bases da Educação Nacional - LDBEN no 9.394/96 (BRASIL, 1996), que em seu artigo 29 regulamenta e define a Educação Infantil como "primeira etapa da educação básica, [que] tem como finalidade o desenvolvimento integral da criança de até 5 (cinco) anos, em seus aspectos físico, psicológico, intelectual e social, complementando a ação da família e da comunidade". As Diretrizes Curriculares Nacionais para a Educação Infantil - DCNEI (BRASIL, 2010) definem a Educação Infantil a partir da LDBEN, oferecida em creches e pré-escolas, em estabelecimentos educacionais públicos ou privados, em jornada integral ou parcial, que devem ser regulados e supervisionados por órgão competente do sistema de ensino e submetidos a controle social.

À medida que essa etapa é compreendida como essencial à formação das crianças, em que suas especificidades sejam consideradas e validadas em um trabalho que as enxergue como seres em potencial, sujeitos históricos, de direitos, em constante aprendizagem, é importante elucidar os conceitos de cuidar e educar dentro das instituições 
de Educação Infantil e da indivisibilidade desse binômio. Salles e Faria $(2012$, p. 67) explicam que: "Cuidar traz a ideia de preservação da vida, de atenção, de acolhimento, envolvendo uma relação afetiva e de proteção. Cumpre o papel de propiciar ao outro bem-estar, segurança, saúde e higiene". Complementam explicitando que: "Educar tem a conotação de orientar, ensinar, possibilitar que o outro se aproprie de conhecimentos e valores que favoreçam seu crescimento pessoal, a integração e a transformação do seu meio físico e social."

Com base nessas concepções e normatizações que orientam profissionais que atuam nessa etapa do ensino, é que a formação acadêmico-profissional ${ }^{3}$ aparece como ação que qualifica a coordenação pedagógica, responsável por assessorar a formação dos professores. Assim, percebemos a importância de articular e ampliar saberes sobre educação e Neurociência, a partir de referenciais teóricos que possam dar consistência teórico-prática, criatividade metodológica e segurança ao exercício profissional.

Como possibilidade de compartilhar saberes, a universidade dialoga com as escolas e vice-versa, mediando reflexões coletivas. A Educação Básica e a Educação Superior articuladas, tecendo e compartilhando conhecimentos, oferecem uma oportunidade ímpar em fortalecer a escola como espaço de formação, de pesquisa, de produção de conhecimentos, revigorando as práticas escolares e validando saberes. Diniz-Pereira (2011) argumenta sobre a formação acadêmico-profissional de professores, que é importante: "conceber o ensino como uma atividade profissional apoiada em um sólido repertório de conhecimentos, entender a prática profissional como um lugar de formação e de produção de saberes pelos práticos e estabelecer ligação entre as instituições universitárias de formação e as escolas da Educação Básica" (p. 213).

A formação em Neurociência colabora com os profissionais da educação para ampliar o entendimento do processo ensino-aprendizagem, no uso de estratégias pedagógicas mais adequadas para o desenvolvimento das funções cerebrais e a melhoria da aprendizagem. Assim, este estudo investigativo apresenta alguns resultados da interface Neurociência e Educação Infantil.

\section{PROCEDIMENTOS METODOLÓGICOS}

Este artigo é resultado de pesquisa ${ }^{4}$ social, descritiva, com abordagem qualitativa (MINAYO; DESLANDES;NETO; GOMES, 1994), que teve como objeto de estudo a investigação de concepções e estratégias metodológicas de coordenadoras pedagógicas da Educação Infantil de uma rede pública municipal de ensino para o assessoramento à práxis pedagógica, na perspectiva da Neurociência. A pesquisa envolveu seis coordenadoras pedagógicas (aqui identificadas pelas letras CP seguidas de numeração cardinal) da primeira etapa da Educação Básica que atuam em três unidades educacionais, aten-

Diniz-Pereira (2008) propõe a expressão formação acadêmico-profissional em substituição às expressões "formação
inicial" e "formação continuada", na perspectiva de que a formação do profissional da educação seja realizada pelo
estabelecimento de parcerias conjuntas entre universidades e escolas de Educação Básica.
Esta pesquisa faz parte de uma pesquisa guarda-chuva que investiga a formação acadêmico-profissional de
profissionais do magistério e a inovação pedagógica, com aprovação pelo Comitê de Ética em Pesquisa da
Universidade. Os sujeitos da pesquisa assinaram o Termo de Consentimento Livre e Esclarecido (TCLE) e o
responsável pela Secretaria Municipal de Educação assinou o Termo de Autorização para a realização da pesquisa. 
dendo crianças de quatro meses a cinco anos de idade (creche e pré-escola), nos seguintes procedimentos investigativos: 1ㅇ) aplicação de entrevista semiestruturada com um roteiro de questões relacionadas à prática pedagógica, ao processo ensino-aprendizagem e à Neurociência: concepção de aprendizagem, de ensino, do processo ensino-aprendizagem, de Educação Infantil e de criança; entendimento de Neurociência, de Neurociência aplicada à educação, de interdisciplinaridade e de inovação pedagógica; organização do currículo e das estratégias metodológicas para esta etapa da Educação Básica; 2) realização de encontros de formação mensais na Secretaria Municipal de Educação (Semed) e em parceria com a Universidade; 3ํ) acompanhamento da práxis educativa in loco, a fim de assessorar e observar aspectos relacionados à Neurociência aplicada à educação.

O grupo de coordenadoras pedagógicas investigado participou de encontros de formação mensais na Semed e das formações em parceria com a Universidade, com a intenção de qualificar a sua práxis junto aos professores que acompanham e assessoram nas instituições de Educação Infantil. Essas profissionais assumem a responsabilidade de fazer da escola um importante espaço de formação acadêmico-profissional.

As entrevistas semiestruturadas foram realizadas no local de trabalho das coordenadoras pedagógicas, gravadas e transcritas na íntegra. Dezessete categorias de análise a priori embasaram as questões elaboradas para as entrevistas, e, no decorrer da investigação, emergiram mais duas, pois as categorias foram se complementando e/ou se auto-organizando à medida que o trabalho foi se constituindo (MORAES; GALIAZZI, 2011).

Nos encontros de formação com o grupo de coordenação pedagógica foram abordados aspectos relacionados à Neurociência aplicada à educação e às metodologias inovadoras, como: Neurociência e educação (avanços e desafios); Neurociência e aprendizagem na Educação Infantil: processo de aprendizagem, processo de ensinar, aspectos socioemocionais envolvidos no processo de ensinar e aprender; desenvolvimento motor infantil; interdisciplinaridade e inovação pedagógica; organização do currículo e das estratégias metodológicas para esta etapa da Educação Básica. Nesses encontros foram feitas anotações em relatórios, a partir das observações que foram objeto de análise.

Concomitantemente à formação, foi realizado o acompanhamento in loco das seis coordenadoras pedagógicas nas instituições de Educação Infantil que atuam. As visitas aconteceram a partir de uma pauta com objetivos e conteúdos que auxiliavam no foco das discussões e observações na escola. Essas pautas não se destinavam apenas aos conteúdos constantes nesta pesquisa, pois envolviam um programa de formação em rede focado a colocar em ação as DCNEls, abordando protagonismo infantil, leitura e escrita pela criança e o brincar nas escolas de Educação Infantil; porém o olhar investigativo afinou para as questões pertinentes à Neurociência, percebidas em muitas ações cotidianas das escolas, nos encaminhamentos e nas falas das coordenadoras pedagógicas. Os registros dos referidos acompanhamentos também constituíram os relatórios investigativos.

Para análise do corpus da pesquisa, resultantes dos três procedimentos investigativos, referidos anteriormente, teve aproximações aos procedimentos de Análise Textual Discursiva (ATD), proposta pelos autores Moraes e Galiazzi (2011), destacando-se que o processo de análise envolveu os seguintes momentos: (a) leitura dos achados; (b) 
desconstrução dos textos do corpus, com organização dos achados em quadros de análise; (c) unitarização: organização das unidades de significado "identificadas em função do sentido pertinente ao propósito da pesquisa" (Ibidem, 2011, p. 19); (d) categorização: reagrupamento das unidades de significado com sentidos semelhantes em cinco categorias de análise, apresentadas no Quadro 1 (e) construção do metatexto: elaboração da escrita de um texto, a partir das categorias levantadas e analisadas teórico-criticamente, que envolveu "o captar o emergente em que a nova compreensão [que] é comunicada e validada" (Ibidem, p. 12).

\section{Quadro 1 - Categorias de Análise}

\begin{tabular}{|c|c|}
\hline Categorias & Entendimentos das CPs \\
\hline $\begin{array}{l}\text { 1. Concepção de } \\
\text { Educação Infantil e } \\
\text { de criança }\end{array}$ & $\begin{array}{l}\text { *Primeira etapa da Educação Básica. *Preparação para o Ensino Fundamental. } \\
\text { * Desenvolvimento de habilidades, janelas de oportunidades, período de muitas } \\
\text { experiências, interações e trocas. *Importante para a formação integral da } \\
\text { criança, criança com muito potencial. *Ser em desenvolvimento, ativo, curioso. } \\
\text { *Protagonista de sua aprendizagem *Ser integral, social. *Ser de direitos. *Precisa } \\
\text { de cuidados e ensino. *Ser com grande potencial para aprender. }\end{array}$ \\
\hline $\begin{array}{l}\text { 2. Processo ensino- } \\
\text { aprendizagem na } \\
\text { Educação Infantil }\end{array}$ & $\begin{array}{l}\text { *Interações com outras crianças, adultose objeto do conhecimento. *Brincadeiras/ } \\
\text { ludicidade/atividades desafiadoras/investigação. *Oportunidades significativas } \\
\text { para aprender. *Aprendem a partir de suas experiências prévias. *Respeito } \\
\text { às especificidades etárias. *Protagonismo infantil. *Sensorial/inteligências } \\
\text { múltiplas/resolução de problemas. *Espaços organizados e intencionais/boas } \\
\text { situações de aprendizagem. }\end{array}$ \\
\hline $\begin{array}{l}\text { 3. Papel do professor } \\
\text { no processo ensino- } \\
\text { aprendizagem }\end{array}$ & $\begin{array}{l}\text { * Mediador. *Reflexivo sobre sua prática docente. *Aquele que oportuniza formas } \\
\text { e estratégias facilitadoras de aprendizagem/propositor. *Incentivador, próximo à } \\
\text { criança. *Planeja com intencionalidade. }\end{array}$ \\
\hline $\begin{array}{l}\text { 4.Neurociênc } \\
\text { Educação Infa }\end{array}$ & $\begin{array}{l}\text { *Estabelece vínculos, confiança, segurança. *Vínculos afetivos favorecem a } \\
\text { aprendizagem, criança mais receptiva para aprender. *Melhora autoestima, } \\
\text { autoconfiança. *Afetividade - "carro chefe" da Educação Infantil. *Entendimento } \\
\text { do funcionamento do cérebro. *Estratégias que atendam a demandas específicas } \\
\text { de aprendizagem. *Entendimento sobre os mecanismos de aprendizagem das } \\
\text { crianças. *Plasticidade cerebral ( } 0 \text { a } 2 \text { anos). *Utilização de todo o cérebro. } \\
\text { *Especificidades etárias. *Conhecimento é cumulativo e contínuo. *Sinapses } \\
\text { - rede de informações. *Desenvolvimento (motor, cognitivo, social e afetivo). } \\
\text { *Envolve todos os sentidos. *Intencionalidade no fazer pedagógico. *Conhecer } \\
\text { qual a melhor forma de aprender - inteligências múltiplas. *Meio físico e social- } \\
\text { interferem na aprendizagem. }\end{array}$ \\
\hline $\begin{array}{l}\text { 5. Inovação na } \\
\text { Educação Infantil }\end{array}$ & $\begin{array}{l}\text { *Educação Infantil transita nas diferentes áreas do conhecimento. *Conteúdos } \\
\text { interligados. } \\
\text { *Utiliza metodologia de projetos que aborda vários temas e transita entre } \\
\text { diferentes disciplinas sem distinção. *Proposta nova/atualização/estratégias } \\
\text { diferentes. *Recriar/ver de forma diferente/reinventar/maneiras novas para } \\
\text { propor as mesmas coisas/Ser algo novo ou ter um novo olhar sobre aquilo } \\
\text { que já se faz/Precisa estar sendo reelaborado. *Estratégias que privilegiem o } \\
\text { protagonismo. *Propostas que trazem a aproximação com a cultura escrita, } \\
\text { brincar como forma inerente da criança aprender. *Indissociabilidade no educar } \\
\text { e cuidar. *Espaços organizados que provoquem as crianças a explorar e aprender. } \\
\text { *Escolas de Educação Infantil ocupadas pelas crianças, com menos produções e } \\
\text { interferências dos adultos. }\end{array}$ \\
\hline
\end{tabular}

Fonte: Elaboração própria.

Com os resultados obtidos da pesquisa é possível refletir, discutir, construir e reconstruir as propostas pedagógicas das instituições de Educação Infantil e dos planos de ação das coordenadoras pedagógicas, com conhecimentos básicos da Neurociência 
e metodologias inovadoras que valorizem as especificidades desta etapa educacional, percebendo a escola como um espaço formativo e significativo para professores e alunos. Na sequência, as análises desta pesquisa culminaram na escrita a seguir.

\section{CONVERSA ENTRE NEUROCIÊNCIA E EDUCAÇÃO INFANTIL: Resultados a Partir dos Achados}

A Neurociência tem papel importante na educação, uma vez que contribui para o entendimento de questões diretamente envolvidas no processo ensino-aprendizagem, como o funcionamento do cérebro, órgão responsável pela aprendizagem, e na proposição de estratégias que facilitem esse processo, que levam em consideração os mecanismos utilizados pelo cérebro para aprender e formar novas conexões neurais. De acordo com Cosenza e Guerra (2011, p. 143): “Os avanços da Neurociência possibilitam uma abordagem mais científica do processo ensino-aprendizagem, fundamentada na compreensão dos processos cognitivos envolvidos". Aspectos importantes auxiliam o entendimento e a compreensão do desenvolvimento humano e, com isso, propostas que contribuem para que o processo ensino-aprendizagem ocorra de forma mais coerente, lúdico, contextualizado, criativo, inovador, reflexivo.

O diálogo entre Neurociência e educação é saudável, necessário e profícuo. Ambas, apesar de conterem peculiaridades, concorrem para a formação do ser humano e buscam promover práticas aprofundadas e coerentes que valorizam singularidades, potencialidades e limitações de cada indivíduo. Também auxiliam no planejamento intencional que privilegia as diferentes formas de aprender, as especificidades relacionadas às idades, a organização dos espaços educacionais, as emoções envolvidas, a empatia com o objeto de conhecimento e a escolha de metodologias e intervenções adequadas e que possam remeter a resultados positivos na aprendizagem.

Muitos aspectos no discurso das coordenadoras pedagógicas evidenciam a importância dos estudos da Neurociência na Educação Infantil, como no processo ensino-aprendizagem expresso na fala da CP06: "A aprendizagem se dá através do contato com o mundo externo, com o objeto de conhecimento e, a partir do momento que eu vou estar utilizando da minha visão, da minha audição para aprender, para vivenciar, eu estou aprendendo [...] eu estou somatizando as informações que estou recebendo", aspectos esses complementados pelas colocações da CP03: "A criança tem diferentes formas de aprender, em cada etapa ela aprende de uma forma, então durante o desenvolvimento dela, de zero aos seis anos, ela vai aprender de diferentes formas, por isso a necessidade de sempre estar proporcionando aprendizagens significativas, atividades que levem a novos conhecimentos, não sempre a mesma coisa."

Coadunamos com Cosenza e Guerra (2011, p. 145) que observam: "Ao conhecer o funcionamento do sistema nervoso, os profissionais da educação podem desenvolver melhor seu trabalho, fundamentar e melhorar sua prática diária, com reflexos no desempenho e na evolução dos alunos". Isso é evidenciado nas colocações de CP01, que entende que a Neurociência "nos aproxima de entender como funciona todo esse processo (de aprendizagem)", enquanto que CP02 destaca que é "O que acontece lá dentro 
do cérebro que faz com que a criança aprenda ou que a criança não consiga aprender" e CP05 entende que "A Neurociência está envolvida em todo o desenvolvimento da criança, cognitivo, motor, socioafetivo".

$\mathrm{Na}$ inter-relação Neurociência e educação, os estudos de Tokuhama-Espinosa (2008) abordam três campos de atuação - Neurociência, Psicologia e Educação - e a colaboração que cada área pode trazer ao ensino, somando saberes, conhecimentos e competências, visando a práticas educacionais compartilhadas, interdisciplinares e significativas. Zaro et al. (2010) apresentam a importância desta inter-relação entre as áreas aos educadores na melhoria de suas práticas em sala de aula, exemplificando o aproveitamento do "conhecimento já consolidado sobre as mudanças neuronais que ocorrem no cérebro, durante o aprendizado (área de pesquisa das Neurociências)", conjugado às "técnicas e métodos de observação e documentação dos comportamentos observáveis (área de pesquisa da Psicologia), para fundamentar de forma consistente e verificável a eficiência de tais práticas" (ZARO et al., 2010, p. 202-203).

Esta aproximação entre educação e Neurociência possibilita refletir sobre como se dá a formação dos profissionais da educação, como os coordenadores pedagógicos, e se há espaços para estudar essas áreas. As coordenadoras pedagógicas da Educação Infantil buscam definir sua identidade neste contexto de formar e formar-se. Tarefa árdua diante de tantas situações que envolvem o cotidiano escolar e das atribuições pertinentes a essa função. Constitui-se um grande desafio para a coordenadora olhar-se como mediadora e colaboradora na formação dos professores, como alguém que acolhe, entende, respeita as dificuldades e individualidades de seu grupo; mas que, ao mesmo tempo, tem a tarefa de ajudar os educadores a trilharem caminhos que Ihes permitam crescimento profissional e pessoal no exercício da docência. Como explicita Vasconcellos (2006, p. 89), "o coordenador, ao mesmo tempo em que acolhe e engendra, deve ser questionador, desequilibrador, provocador, animando e disponibilizando subsídios que permitam o crescimento do grupo (...)". Pressupõe também compreender as formas como as crianças aprendem e se desenvolvem, conhecer as características das fases do desenvolvimento infantil, para ter condições de orientar estudos, assessorar os professores no exercício da docência e no processo ensino-aprendizagem por meio de práticas interacionistas e lúdicas, na indissociabilidade do cuidar e educar, em acordo com as DCNEIs (BRASIL, 2010, p. 18).

Assim, nas práticas da Educação Infantil, vários aspectos são considerados, entre eles a forma como são percebidas, organizadas e valorizadas no cotidiano da instituição infantil, os tempos, espaços e materiais que devem garantir a educação integralizada, a interdisciplinaridade, os desafios que promovam aprendizagens significativas e contextualizadas, sempre respeitando as especificidades etárias. As DCNEIs (BRASIL, 2010, p. 19) destacam, entre outros aspectos, "a indivisibilidade das dimensões expressivo-motora, afetiva, cognitiva, linguística, ética, estética e sociocultural da criança".

Nesse sentido, o princípio da interdisciplinaridade encontra na Educação Infantil espaço favorável, pois o currículo divide-se em campos de experiências, "que se articulam com os conhecimentos e saberes, tendo em vista alcançar determinados objetivos" (SALLES; FARIA, 2012, p. 78), propiciando naturalmente, no desenvolvimento das atividades, a conversa entre as diferentes áreas do saber, principiando a integralidade 
da criança. Esse entendimento também foi notado nas respostas das coordenadoras, ao serem questionadas sobre interdisciplinaridade: "O professor de Educação Infantil consegue trabalhar com todas as áreas, sem dizer: agora vamos abrir a gavetinha da linguagem, agora vamos abrir a gavetinha da matemática" (CP04). A Neurociência aparece entreposta à referência aos sentidos atribuídos às experiências vivenciadas e à compreensão aplicada em seus contextos de vida. As crianças entram em contato com diferentes saberes, formam conceitos simples e, no percurso em contextos variados, ampliam sua rede de informações formando conceitos mais complexos e formais. Lima $(2008$, p. 46) expressa que o "conceito se constitui ao longo de um tempo e de forma organizada. Ele caminha no sentido da complexidade crescente: o aluno desenvolve conceitos com menos elementos para conceitos mais abrangentes, com mais elementos."

A CP06 também comenta que: "Não temos aquela coisa muito fragmentada, é muito interligada a questão da interdisciplinaridade. A gente consegue abordar no mesmo momento a questão da linguagem, a questão do raciocínio lógico, a questão das ciências, do cuidado com o meio, consigo mesmo. Não tem as janelinhas fechadinhas $[\ldots]$ ". No discurso da coordenadora há a clareza de que a aprendizagem precisa ocorrer de forma dialogada, contextualizada, significativa, em que o objeto do conhecimento se faz conhecer, integrando diferentes campos do saber e considerando a criança na sua totalidade. Machado (2010, p. 51) entende o conhecimento "como uma totalidade que engloba aspectos sociais, individuais, cognitivos, afetivos, a presença dos conceitos advindos da experiência direta e daquelas que são fruto de uma elaboração complexa, conferem valor e sentido ao espaço institucional dirigido a crianças de zero a seis anos." A Neurociência assessora na compreensão desse processo.

Vasconcellos (1992, p. 2) expõe que a metodologia dialética coloca o aluno numa situação dinâmica diante do conhecimento, "um ser ativo e de relações" e que o "conhecimento é construído pelo sujeito na sua relação com os outros e com o mundo". Aqui são evidenciados os princípios da interdisciplinaridade e da contextualização tão necessários à prática educativa. A relação sujeito-objeto e conhecimento-mundo é evidenciada pelos estudos de Freire (1987), no processo de reflexão sobre a ação transformadora e criadora implicada pelo homem à medida que age e se relaciona no meio em que está inserido, inferindo significados, produzindo cultura, saberes e se recriando a todo momento. Traz a ideia de ser inacabado, inconcluso, que se constrói, aprende continuamente no contato com os outros e com o objeto do conhecimento.

A importância do ambiente e as interações que nele se estabelecem são percebidas, pois quanto mais ricas em oportunidades essas interações acontecerem maior significância terão as aprendizagens. Cosenza e Guerra (2011, p. 34) se posicionam no sentido de que: "A interação com o ambiente é importante porque é ela que confirmará ou induzirá a formação de conexões nervosas e, portanto, a aprendizagem ou o aparecimento de novos comportamentos que delas decorrem.". Assim sendo, é imprescindível que o currículo seja repleto de vivências e experiências oportunizadas em diferentes linguagens e que alarguem os saberes das crianças sobre o mundo e, ao mesmo tempo, somem e associem-se aos conhecimentos prévios e já estruturados por elas. 
Cosenza e Guerra (Ibidem, p. 36) expressam que "a aprendizagem pode levar não só ao aumento da complexidade das ligações em um circuito neural, mas também à associação de circuitos até então independentes. É o que acontece quando aprendemos novos conceitos a partir de conhecimentos já existentes". Essa ideia também é expressa pelas coordenadoras que dizem: "[...] A criança não é uma folha em branco, ela já vem de casa, já traz da comunidade onde vive, da sociedade os seus conhecimentos prévios" (CPO3), complementado pela CPO4, que comenta que "Ela forma opinião, ela forma conceitos a partir daquilo que vivencia. Não adianta só falar para as crianças nessa faixa etária da Educação Infantil... ela tem que tocar, sentir...ela tem que vivenciar. Aí ela aprendeu e a aprendizagem se torna significativa".

Nesse aspecto Lima (2008, p. 25) recorre à Neurociência para explicar que:

A ação da criança depende da maturação orgânica e das possibilidades que o meio Ihe oferece: ela não poderá realizar uma ação para a qual não tenha o substrato orgânico, assim como não fará muitas delas, mesmo que biologicamente apta, se a organização do seu meio físico e social não propiciar sua realização ou se os adultos não a ensinarem.

Seguindo essa lógica, as instituições de Educação Infantil pesquisadas organizam as experiências a serem vivenciadas e os saberes e conhecimentos a serem construídos a partir de projetos de trabalho que "constituem um planejamento de ensino e aprendizagem vinculado a uma concepção da escolaridade em que se dá importância não só à aquisição de estratégias, mas também ao papel do estudante como responsável por sua própria aprendizagem" (HERNÁNDEZ, 1998, p. 88-89). Os temas normalmente disparam a partir de alguma questão que tenha despertado o interesse das crianças, constituindo-se em problema a ser resolvido, valendo-se da investigação, pesquisa, mobilização de conhecimentos prévios e aquisição de novas informações.

As coordenadoras entrevistadas destacam essa forma de organização por projetos como fator que favorece a interdisciplinaridade e que leva em conta as características das crianças nesta idade em termos de interesse e interação com o objeto do conhecimento, com seus pares e adultos, pela pesquisa e produções contextualizadas que consideram saberes prévios, se conectam a novas informações e resultam em aprendizagens que irão alicerçar conteúdos mais complexos no futuro, como na exposição da CP06: "Na elaboração dos projetos, no desenvolvimento das atividades, a gente consegue elencar atividades de várias áreas do conhecimento, fazendo essa abordagem interdisciplinar. As áreas conversam entre si, sem separar, trazem uma abordagem rica". A CP04 também reforça que o trabalho com projetos e temáticas possibilita outra perspectiva da interdisciplinaridade: "A gente trabalha com projetos e no projeto a professora trabalha com todas as possibilidades. De um tema, ela cria várias redes do conhecimento que vai atingir todas as áreas".

Vygotski (apud CRAIDY; KAERCHER, 2001) contribui significativamente para compreensão da cognição humana. Para esse autor (apud FELIPE, 2001), o conhecimento é construído a partir das interações sociais com outros sujeitos e com o mundo exterior, que são mediadas e articuladas por meio da linguagem. Felipe (2001, p. 29) observa que Vygotski afirma que "a relação dos indivíduos com o mundo não é direta, mas me- 
diada por sistemas simbólicos, em que a linguagem ocupa um papel central, pois além de possibilitar o intercâmbio entre os indivíduos, é através dela que o sujeito consegue abstrair e generalizar o pensamento".

Outra questão importante apontada pelo teórico Vygotski (VIGOTSKII, 2010) são os níveis do processo de desenvolvimento: a) nível de desenvolvimento efetivo - refere-se ao que a criança é capaz de resolver ou fazer sozinha, sem ajuda. b) nível de desenvolvimento potencial - diz respeito ao que a criança consegue realizar com a mediação ou ajuda de outra pessoa. É na zona de desenvolvimento potencial que vão ocorrer as intervenções do adulto para que a criança avance, concorrendo para novas e significativas aprendizagens. Neste aspecto aponta a brincadeira, principalmente o jogo simbólico, como fundamental para o desenvolvimento infantil.

Com o auxílio da imitação na atividade coletiva guiada pelos adultos, a criança pode fazer muito mais do que com a sua capacidade de compreensão de modo independente. A diferença entre o nível das tarefas realizáveis com o auxílio dos adultos e o nível das tarefas que podem desenvolver-se com uma atividade independente define a área de desenvolvimento potencial da criança (VIGOTSKII, 2010, p. 112).

O jogo simbólico, na Educação Infantil, é representado nas brincadeiras de faz-de-conta, em que as crianças vivenciam diferentes situações do cotidiano, procurando entendê-las e antecedendo eventos que, mais tarde, farão parte de sua vida. Lima (2008, p. 27) destaca que "o desenvolvimento da função simbólica no ser humano é de extrema importância, uma vez que é por meio do exercício desta função que o ser humano pode construir significados e acumular conhecimentos."

Durante as brincadeiras a criança mostra-se por inteiro, vivencia as mais variadas situações, é envolvida por diferentes sentimentos, experimenta o mundo pelos sentidos, movimenta-se e aprende a reconhecer-se na individualidade e no coletivo. Santos (2001, p. 89) define o espaço do jogo "como um espaço de experiência e liberdade de criação no qual as crianças expressam suas emoções, sensações e pensamentos sobre o mundo e também um espaço de interação consigo mesmas e com os outros."

As crianças precisam brincar e conviver com outras crianças da mesma faixa etária, de idades diferentes e com adultos. Nesta tarefa, os adultos que trabalham com as crianças têm função primordial de mediar as brincadeiras, colocando-se junto a elas, interferindo o menos possível, porém observando atentamente os enredos que se desencadeiam, as questões que emergem a fim de alimentar, provocar, inserir elementos que possam enriquecer e ampliar esses enredos, promovendo a criança à protagonista de suas ações e aprendizagens. Essa ideia também é expressa pela CP06 ao expressar que: "Aprendizagem se dá através das interações, no momento que a criança tem interação com o objeto do conhecimento, interação com o outro, aquilo se torna significati$v{ }^{\prime \prime}$. Nessas trocas emergem saberes, as crianças menos experientes aprendem com os mais experientes; é na relação com os outros que constrói sua identidade, se vê como pertencente a um determinado grupo social, aprende e incorpora a cultura e os saberes de sua comunidade. Salles e Faria (2012, p. 121) complementam esclarecendo que é no espaço lúdico que as crianças "aprendem a interagir, a construir e a reconstruir as 
relações sociais como sujeitos competentes, membros participantes e integrados num grupo. A criação de regras, às quais todos devem se submeter, além de permitir ao grupo se autoestruturar, possibilita a cooperação entre as crianças".

A Neurociência pode auxiliar a entender os processos envolvidos para que as crianças se desenvolvam e aprendam dentro de um contexto rico, que lhes oportunize múltiplas experiências sensoriais, sociais, afetivas, cognitivas; sendo respeitadas integralmente, na sua saúde física e mental, colaborando para que se torne uma pessoa capaz de agir e intervir na sociedade de forma crítica, consciente, autônoma, responsável e feliz.

\section{FORMAÇÃO E ACOMPANHAMENTO DAS PRÁTICAS EDUCATIVAS NA EDUCAÇÃO INFANTIL E SUA RELAÇÃO COM A NEUROCIÊNCIA}

A formação acadêmico-profissional é fundamental no processo de apropriação e qualificação do trabalho da coordenação pedagógica, pois possibilita tornar a escola um espaço contínuo de formação, reflexão, avaliação, (re)construção de saberes e práticas, com a intenção de transformar, quebrar paradigmas, reavivar interesses e provocar mudanças de postura, atitudes e concepções. Sobre isso, Diniz-Pereira (2015) acentua que:

Precisamos romper com a concepção da escola "apenas" como um espaço para se ensinar. Temos que passar a enxergar esse espaço como local de produção de conhecimentos e saberes; um local onde identidades individuais e sociais são forjadas, onde se aprende a ser sujeito, cidadão crítico, participativo - atuante em sua comunidade - e responsável (2015, p. 147).

Nesse sentido, a partir das formações organizadas e desenvolvidas pela Semed e em parceria com a Universidade, as coordenadoras pedagógicas desenvolveram formações em suas escolas, acolhendo e observando os diferentes contextos, demandas e singularidades de todos os segmentos que fazem parte dessa instituição. Essa estratégia possibilitou e garantiu a formação em rede, proporcionando que todos os segmentos (funcionários, professores e gestores) participassem efetivamente das discussões, estudos, reflexões acerca dos conteúdos e/ou temáticas apresentadas. Outra estratégia verificada foi o aprofundamento dos conteúdos, que foram amplamente discutidos em vários encontros, de forma dialógica e reflexiva, oportunizando aos profissionais envolvidos repensarem sobre sua identidade e prática docente.

Com olhar sensível dos dirigentes da Semed, foi garantido espaço-tempo para a formação dos profissionais nas escolas como condição básica de valorização da escola como local de construção e reconstrução de saberes e dos próprios profissionais que se veem em constante transformação, tanto na sua identidade individual como no coletivo institucional. Refletir conjuntamente sobre as práticas pedagógicas desenvolvidas na instituição colabora para o crescimento do grupo envolvido e na qualidade do trabalho docente. Nessa perspectiva, Nóvoa (1999, p. 10) aconselha que "os professores têm de redescobrir uma identidade coletiva, que lhes permita cumprir o seu papel na formação das crianças e dos jovens". Os momentos de formação instigaram as coordenadoras pedagógicas e os demais sujeitos envolvidos a olhar a criança como ser potente, criativo, capaz de aprender e se manifestar por meio de diferentes linguagens. 
Nessa perspectiva, os adultos precisam conhecer as especificidades da primeira infância para que possam atuar como mediadores, oportunizando momentos de experiências variadas e ricas em ambientes intencionalmente planejados para alimentar a imaginação, a curiosidade, a resolução de problemas, a aplicabilidade de conhecimentos prévios e construção de novos saberes, as interações com adultos e crianças de diferentes idades. Para complementar essa ideia, as DCNEIs (BRASIL, 2010, p. 12) definem criança como: "Sujeito histórico e de direitos que, nas interações, relações e práticas cotidianas que vivencia, constrói sua identidade pessoal e coletiva, brinca, imagina, fantasia, deseja, aprende, observa, experimenta, narra, questiona e constrói sentidos sobre a natureza e a sociedade, produzindo cultura."

Diante desse processo de formação e de (re)significação da prática, o grupo de coordenação pedagógica considerou a Neurociência como ciência que ajuda a repensar a educação de forma inovadora e essencial para compreender o desenvolvimento e crescimento infantil, o processo ensino-aprendizagem, a importância dos vínculos afetivos estabelecidos nas relações com adultos e crianças, a valorização das interações, do brincar e demais aspectos abordados e emergidos nos encontros, principalmente no cotidiano das coordenadoras pedagógicas dentro da instituição. Foi possível enxergar a criança integralmente e como protagonista, no sentido de participar de todo o processo de criação e tomadas de decisão e não apenas ser reprodutora ou coadjuvante das atividades escolares e vontade dos adultos, de ser ouvida com atenção e interesse, respeitada em suas subjetividades.

Penha (2016, p. 61) adverte que "a inovação curricular parte de uma intenção consciente de mudança de uma determinada situação, com base em uma crença de que esta situação pode ser organizada de modo diferente do usual." Para que isso aconteça, destaca "o desejo do professor em ousar, em favorecer novas ações planejadas e orientadas por finalidades específicas da realidade educacional de cada situação particular" (Ibidem).

Estabelecer, portanto, relações com a Neurociência na Educação Infantil é procurar assimilar a complexa relação do desenvolvimento das funções cerebrais, seus mecanismos biológicos que inferem diretamente na aprendizagem, no comportamento e na saúde das crianças no decorrer de sua vida. Para Bartoszeck e Bartoszeck (2013, p. 9), "Parece que uma vez que os sistemas de regulação, por exemplo o emocional, se organiza nos primórdios da vida, é difícil modificá-los mais tarde". Complementam ainda: "Uma das coisas mais fascinantes para a criança é perceber que está sempre aprendendo" (Ibidem).

Daí a importância de as instituições infantis assegurarem um ambiente emocionalmente positivo em que as crianças sejam educadas e cuidadas num clima de afeto e responsabilidade, em que se sintam respeitadas e atendidas nas suas necessidades, desejos, curiosidades e, ao mesmo tempo, tenham oportunidades de estar sempre aprendendo. Bartoszeck e Bartoszeck (2013, p. 15) afirmam que:

Estimulação sensorial positiva, como carinho da mãe, fortalece e aumenta a longevidade sináptica. Esta condição, presume-se, reflete no desenvolvimento cognitivo acelerado, emoções equilibradas, apego e capacidade de responder positivamen- 
te a novas experiências. Na negligência extremada quando a criança é privada de qualquer afeto e atenção da mãe, reduzem-se as chances da criança vir a ter bom desempenho na escola, e na futura vida afetiva.

Cientes dessas premências, a formação das coordenadoras foi organizada tendo na pauta de discussão temáticas relacionadas à Neurociência e que contribuíssem para qualificar as práticas pedagógicas nas instituições infantis. No Quadro 2, a seguir, estão sintetizadas as temáticas, com os respectivos aspectos relacionadas à Neurociência, abordadas nos encontros de formação realizados no período de agosto a dezembro de 2016 na Semed.

Quadro 2 - Encontros de formação das coordenadoras pedagógicas

\begin{tabular}{|c|l|c|}
\hline Temáticas & \multicolumn{1}{|c|}{ Aspectos da Neurociência envolvidos } & $\begin{array}{c}\text { Responsável pela } \\
\text { formação }\end{array}$ \\
\hline $\begin{array}{c}\text { Neurociência e } \\
\text { educação }\end{array}$ & $\begin{array}{l}\text { Aprendizagem, plasticidade cerebral, mitos e verdades } \\
\text { sobre Neurociência, aspectos socioemocionais envolvidos } \\
\text { no processo de ensinar e aprender. }\end{array}$ & $\begin{array}{c}\text { Profissional da } \\
\text { universidade }\end{array}$ \\
\hline $\begin{array}{c}\text { Desenvolvimento } \\
\text { motor infantil }\end{array}$ & $\begin{array}{l}\text { Aspectos relacionados ao desenvolvimento e crescimento } \\
\text { infantil. }\end{array}$ & $\begin{array}{c}\text { Profissionais da } \\
\text { universidade }\end{array}$ \\
\hline $\begin{array}{c}\text { Organização dos } \\
\text { espaços escolares. }\end{array}$ & $\begin{array}{l}\text { Protagonismo infantil, relação cognitiva e afetiva } \\
\text { estabelecida com os livros e interações entre as crianças e } \\
\text { adultos nesses espaços, sensibilização estética, mobilização } \\
\text { de conhecimentos. }\end{array}$ & $\begin{array}{c}\text { Formadoras da } \\
\text { Semed }\end{array}$ \\
\hline $\begin{array}{c}\text { Ações formativas da } \\
\text { equipe gestora }\end{array}$ & $\begin{array}{l}\text { Coprotagonismo adulto, especificidades etárias, } \\
\text { plasticidade cerebral, desenvolvimento infantil, mobilização } \\
\text { de conhecimentos, afetividade. }\end{array}$ & $\begin{array}{c}\text { Formadoras da } \\
\text { Semed }\end{array}$ \\
\hline $\begin{array}{c}\text { Protagonismo infantil: } \\
\text { brincar, cultura escrita } \\
\text { e linguagem. }\end{array}$ & $\begin{array}{l}\text { Sensibilização estética, mobilização de conhecimentos, } \\
\text { interações que promovam conhecimentos, empatia, } \\
\text { interesse, emoção e aprendizagem. Processo ensino- } \\
\text { aprendizagem, desenvolvimento infantil. }\end{array}$ & Formadoras da \\
Semed
\end{tabular}

Fonte: Elaboração própria.

Ficou evidente a importância dessa formação e a sua continuidade na escola para ampliar as discussões conforme a realidade e perspectiva dos educadores de cada instituição. As visitas nas três escolas acompanhadas in loco, realizadas no segundo semestre (além das formações com todos os segmentos, que foram oportunizadas e desenvolvidas pelas equipes gestoras) tiveram o intuito de acompanhar e assessorar as equipes no desdobramento de seu trabalho. Estes encontros organizavam-se a partir de uma pauta que orientava o foco e desencadeava as discussões. Vale comentar que as pautas não possuíam foco restrito na Neurociência, pois envolviam um programa de formação da rede de ensino, porém a observação deteve-se nos aspectos relacionados à Neurociência presentes nos encaminhamentos, falas e atitudes das coordenadoras. Nem sempre as professoras coordenadoras pedagógicas tinham consciência de que estavam falando ou tratando de Neurociência, por possuírem pouco conhecimento relacionado ao assunto, porém as ações constatadas foram entremeadas por aspectos que conversam direta e indiretamente com esta ciência, revelados no cotidiano escolar.

O acompanhamento in loco possibilitou perceber o quanto a Neurociência está presente na escola e o tanto que sua aproximação com a educação pode ser positiva, auxiliando na compreensão e criação de estratégias que favoreçam o processo ensino- 
-aprendizagem. Consiste aqui um dos maiores desafios da coordenação pedagógica, mobilizar o grupo de educadores a sair da zona de conforto, a desacomodar-se e encontrar novas alternativas que tornem a atividade docente mais atrativa, significativa e humanizada, que venha ao encontro dos interesses e necessidades das crianças.

Como explicita Guerra (2011, p. 2), as "funções relacionadas à cognição e às emoções, presentes no cotidiano e nas relações sociais, como sentir e perceber, gostar e rir, dormir e comer, falar e se movimentar, [...] pensar, imaginar, se emocionar, são comportamentos que dependem do funcionamento do cérebro". Assim, a referida autora (Ibidem, p. 6) reforça a importância da Educação Infantil, etapa em que a criança, desde os anos iniciais, fica exposta a "estímulos sensoriais, motores, emocionais e sociais variados, frequentes e repetidos", que "contribuirá para a manutenção das sinapses já estabelecidas, com preservação de comportamentos com os quais nascemos, e para a formação de novas sinapses, resultando em novos comportamentos".

As visitas de acompanhamento aconteceram, num movimento dialógico-reflexivo, aspirando que as discussões passassem do discurso para a prática num processo de apropriação, acolhimento e efetivação. É preciso atenção, escuta, sensibilidade para captar os desejos, anseios, dúvidas surgidas no grupo e trazê-las para o coletivo da formação. O Quadro 3, a seguir, apresenta a ênfase das pautas e os aspectos relacionados à Neurociência durante o acompanhamento in loco nas três escolas pesquisadas.

Quadro 3 - Acompanhamento in loco nas escolas de Educação Infantil

\begin{tabular}{|c|c|c|c|}
\hline \multicolumn{2}{|c|}{$\begin{array}{l}\text { Escolas e } \\
\text { acompanha- } \\
\text { mentos }\end{array}$} & \multirow{2}{*}{\begin{tabular}{|l|}
$\begin{array}{l}\text { Ênfase das pautas de } \\
\text { acompanhamento }\end{array}$ \\
$\begin{array}{l}\text { Protagonismo infantil e } \\
\text { ocupação criança. }\end{array}$ \\
\end{tabular}} & Aspectos observados em relação à Neurociência \\
\hline \multirow{3}{*}{ Escola 1} & 1.1. & & $\begin{array}{l}\text { Criatividade, cognição, afetividade, plasticidade cerebral, } \\
\text { emoção, respeito às especificidades etárias, autonomia. }\end{array}$ \\
\hline & 1.2. & $\begin{array}{l}\text { Cultura escrita e } \\
\text { protagonismo infantil. } \\
\text { comportamento leitor, } \\
\text { leitura para bebês. }\end{array}$ & $\begin{array}{l}\text { Planejamento intencional, provocativo, desafiador, tornar } \\
\text { espaços da escola potentes para aprendizagens significativas } \\
\text { com múltiplas experiências, respeito à singularidade das } \\
\text { crianças com suas histórias de vida, desenvolvimento e } \\
\text { crescimento infantil (habilidades conquistadas), escola como } \\
\text { espaço de escuta das crianças (sentimentos, necessidades, } \\
\text { anseios, desejos, descobertas...). }\end{array}$ \\
\hline & 1.3. & $\begin{array}{l}\text { Socialização de boas } \\
\text { práticas decorrentes das } \\
\text { formações. }\end{array}$ & $\begin{array}{l}\text { Brincar: principal atividade da criança - espaços garantidos } \\
\text { e com potencial para aprendizagens, oportunidade de } \\
\text { experiências variadas e ricas, contato e exploração de } \\
\text { materiais provenientes da natureza com vivências sensoriais } \\
\text { e estéticas (sensibilidade, cuidado, criações artísticas). }\end{array}$ \\
\hline \multirow{3}{*}{ Escola 2} & 2.1. & $\begin{array}{l}\text { Leitura e contação de } \\
\text { histórias para bebês; a } \\
\text { importância de registrar. }\end{array}$ & $\begin{array}{l}\text { Mediação na leitura, proximidade dos educadores, interação } \\
\text { com outras crianças e adultos, relação de empatia com os } \\
\text { livros e histórias contadas, afetividade. }\end{array}$ \\
\hline & 2.2. & $\begin{array}{l}\text { Leitura e escrita pelas } \\
\text { crianças; leitura para } \\
\text { crianças ( } 4 \text { meses a } 3 \\
\text { anos). }\end{array}$ & $\begin{array}{l}\text { Sensibilização, experiências sensoriais, atenção, memória, } \\
\text { percepção, imaginação, criação de hipóteses. }\end{array}$ \\
\hline & 2.3. & $\begin{array}{l}\text { Socialização de boas } \\
\text { práticas decorrentes das } \\
\text { formações. }\end{array}$ & $\begin{array}{l}\text { Brincar: principal atividade da criança, espaços garantidos } \\
\text { e com potencial para aprendizagens, oportunidade de } \\
\text { experiências variadas e ricas, contato e exploração de } \\
\text { materiais provenientes da natureza com vivências sensoriais } \\
\text { e estéticas (sensibilidade, cuidado, criações artísticas). }\end{array}$ \\
\hline
\end{tabular}




\begin{tabular}{|c|c|c|c|}
\hline \multirow{3}{*}{ Escola 3} & 3.1. & $\begin{array}{l}\text { Planejamento } \\
\text { dos professores: } \\
\text { intencionalidade, } \\
\text { atenção à diversidade; } \\
\text { leitura para bebês. }\end{array}$ & $\begin{array}{l}\text { Mobilização de conhecimentos, experiências sensoriais, } \\
\text { atenção, memória, percepção, imaginação, criatividade, } \\
\text { autonomia, exploração de espaços que oportunizam a } \\
\text { expressão de múltiplas linguagens, interação entre pares. }\end{array}$ \\
\hline & 3.2. & $\begin{array}{l}\text { Protagonismo infantil: } \\
\text { ocupação criança; } \\
\text { práticas de leitura e } \\
\text { escrita. }\end{array}$ & $\begin{array}{l}\text { Atenção ao fazer, aos tempos individuais e coletivos das } \\
\text { crianças, planejamento intencional para as crianças e que } \\
\text { possibilitem aprendizagens novas, oferta de oportunidades } \\
\text { ricas em experiências sensoriais, experimentação de } \\
\text { materiais variados, processo criativo na arte, escrita, } \\
\text { leitura...; espaço de construção de relações positivas e } \\
\text { fortalecimento de vínculos, de escuta das crianças, criação } \\
\text { de hipóteses e resolução de problemas. }\end{array}$ \\
\hline & 3.3. & $\begin{array}{l}\text { Socialização de boas } \\
\text { práticas decorrentes das } \\
\text { formações. }\end{array}$ & $\begin{array}{l}\text { Brincar: principal atividade da criança, espaços garantidos } \\
\text { e com potencial para aprendizagens, oportunidade } \\
\text { de experiências variadas e ricas (diferentes contextos } \\
\text { organizados que desafiavam e provocavam a imaginação, a } \\
\text { criação e descobertas), contato e exploração de materiais } \\
\text { provenientes da natureza com vivências sensoriais e estéticas } \\
\text { (sensibilidade, cuidado, criações artísticas). }\end{array}$ \\
\hline
\end{tabular}

Fonte: Elaboração própria.

Nessas três escolas ocorreu envolvimento e apropriação da equipe gestora, principalmente da coordenação pedagógica, que fez a diferença na confiança e efetivação de um trabalho fundamentado nos estudos orientados durante os encontros de formação. Cada escola, por suas singularidades, fez um percurso distinto, e avançaram em ritmos desiguais; contudo ficou nítido que, das escolas investigadas, a que teve uma equipe gestora atuando ao lado de seu grupo, trazendo para a reflexão aspectos observados na prática e discutidos a partir de aportes teóricos consistentes e relacionados com as observações in loco, obteve um crescimento mais significativo em todos os segmentos da escola, com mudanças refletidas na postura dos educadores, na organização dos espaços escolares, no desenvolvimento da prática docente, na não fragmentação dos conteúdos, no olhar e tratamento às crianças manifestados no cuidado, afeto e atenção aos seus interesses e necessidades. A criança foi percebida como sujeito potente e protagonista de sua ação, aspecto esse relacionado à inovação pedagógica juntamente com a Neurociência, que valoriza a infância como etapa de subjetividades e crucial para um desenvolvimento e crescimento saudável.

Os profissionais que atuam na Educação Infantil perceberam a relevância em compreender que nos primeiros anos de vida da criança ocorre uma imensa gama de aprendizagens, com grande plasticidade cerebral, entendida como a "possibilidade de formação de conexões entre neurônios a partir das sinapses" (LIMA, 2008, p. 24) e também a morte de neurônios (poda neuronal) pela pouca ou não utilização de determinadas funções, o que remete aos educadores atenção e busca por conhecer como as crianças aprendem e como devem proceder no processo ensino-aprendizagem.

A partir das diferentes realidades vividas nas instituições de Educação Infantil, a coordenação pedagógica, ao aprimorar seus conhecimentos, forma-se e se constitui formadora de outros professores. O trabalho da coordenação pedagógica, juntamente 
com os demais componentes da equipe gestora, influencia, instiga e provoca mudanças na escola de Educação Infantil, espaço educacional de saberes e fazeres, local de pesquisa e discussão da prática docente articulada com a teoria.

\section{CONSIDERAÇÕES FINAIS}

A Neurociência tem muito a contribuir com a educação, especialmente na primeira infância, e os educadores necessitam apropriar-se dos conhecimentos que essa ciência oferece para aprimorar as práticas pedagógicas nas instituições de Educação Infantil. As coordenadoras pedagógicas possuem a força de mudança, pois são elas que se encontram no contexto escolar, sentindo e vivendo todas as emergências que surgem e que visualizam as fraquezas e potências dentro desse ambiente.

Emerge a continuidade de mobilização para formação acadêmico-profissional com estudos que aprofundem saberes acerca da Neurociência, com a intenção real de aproveitá-la para enriquecer o planejamento escolar com estratégias metodológicas inovadoras que enxerguem a criança de acordo com suas especificidades, necessidades, desejos e, principalmente, como um ser capaz de fazer e aprender, entendendo melhor o funcionamento cerebral. As coordenadoras abraçam essa função como responsáveis por fazer da escola um espaço formativo, porém desnaturalizar práticas e hábitos que se repetem ao longo de anos não é tarefa fácil, mas necessária para atender às demandas que se apresentam no dia a dia nos espaços em que as crianças vivem e convivem.

No acompanhamento da prática e nas narrativas das coordenadoras, ficou evidente que a Neurociência encontra-se entreposta nos planejamentos e nas práticas, mas, em muitos momentos, passa despercebida pelo escasso entendimento que o grupo possui sobre o assunto. Ficou evidente o interesse dessas profissionais em trazer a temática para as pautas de estudos com os professores, a fim de planejar e instituir estratégias pedagógicas na Educação Infantil com suporte significativo da Neurociência.

Nesse sentido, a parceria entre as instituições de Educação Infantil e a universidade mostra-se imprescindível para dar continuidade aos estudos, ampliando, renovando e validando a importância de referenciais que embasam estudos e práticas interessantes relacionadas à Neurociência e à Educação Infantil.

\section{REFERÊNCIAS}

ARIÉS, Philippe. História social da criança e da família. 2. ed. Tradução Dora Flaksman. Rio de Janeiro: Guanabara, 1978.

BARTOSZECK, Amauri Betini; BARTOSZECK, Flavio Kulevicz. Neurociência dos seis primeiros anos: implicações educacionais. 2013. Disponível em: http://neuropsicopedagogianasaladeaula.blogspot.com. br/2013/08/neurociencia-dos-seis-primeiros-anos.html. Acesso em: 21 jul. 2016.

BRASIL. Ministério da Educação. Secretaria de Educação Básica. Diretrizes Curriculares Nacionais para a Educação Infantil. Brasília: MEC; SEB, 2010.

BRASIL. Presidência da República. Casa Civil. Subchefia para Assuntos Jurídicos. Lei n. 9.394, de 20 de dezembro de 1996. Estabelece as diretrizes e bases da educação nacional. Diário Oficial [da República Federativa do Brasil], Brasília, DF, v. 134, n. 248, 23 dez. 1996. Seção 1, p. 27.834-27.841.

CAMBI, Franco. História da pedagogia. Tradução Álvaro Lorencini. São Paulo: Fundação Editora da Unesp (FEU), 1999.

COSENZA, Ramon M.; GUERRA, Leonor B. Neurociência e educação: como o cérebro aprende. Porto Alegre: Artmed, 2011. 
CRAIDY, Carmem Maria; KAERCHER, Gládis Elise P. da Silva (org.). Educação infantil: pra que te quero? Porto Alegre: Artmed, 2001.

DINIZ-PEREIRA, Júlio Emílio. A formação acadêmico-profissional: compartilhando responsabilidades entre as universidades e escolas. In: TRAVERSINI, Clarice et al. (orgs.). Trajetórias e processos de ensinar e aprender: didática e formação de professores. Porto Alegre: Edipucrs, 2008, v. 1, p. 253-267.

DINIZ-PEREIRA, Júlio Emílio. A prática como componente curricular na formação de professores. Educação, Santa Maria, v. 36, n. 2, p. 203-218, maio/ago. 2011.

DINIZ-PEREIRA, Júlio Emílio. Formação de professores, trabalho e saberes docentes. Trabalho \& Educação, Belo Horizonte, v. 24, n. 3, p. 143-152, set./dez. 2015.

FELIPE, Jane. O desenvolvimento infantil na perspectiva sociointeracionista: Piaget, Vygostsky, Wallon. In: CRAIDY, Carmem Maria; KAERCHER, Gládis Elise P. da Silva (org.). Educação infantil: pra que te quero? Porto Alegre: Artmed, 2001.

FREIRE, Paulo. Pedagogia do oprimido. 17. ed. Rio de Janeiro: Paz e Terra, 1987.

GUERRA, Leonor. O diálogo entre a neurociência e a educação: da euforia aos desafios e possibilidades. Interlocução, Belo Horizonte, v. 4, n. 4, 2011.

HERNÁNDEZ, Fernando. Transgressão e mudança na educação: os projetos de trabalho. Tradução Jussara Haubert Rodrigues. Porto Alegre: Artmed, 1998.

LIMA, Elvira Souza. Indagação sobre currículo: currículo e desenvolvimento humano. Brasília: Ministério da Educação; Secretaria de Educação Básica, 2008.

MACHADO, Maria Lucia de A. Educação infantil e sociointeracionismo. In: OLIVEIRA, Zilma de Moraes Ramos de (org.). Educação infantil: muitos olhares. 9. ed. São Paulo: Cortez, 2010.

MINAYO, Maria Cecília de Souza; DESLANDES, Suely Ferreira; NETO, Otávio Cruz; GOMES, Romeu. Pesquisa social: teoria, método e criatividade. 21. ed. Petrópolis: Vozes, 1994.

MORAES, Roque; GALIAZZI, Maria do Carmo. Análise textual discursiva. Ijuí: Editora Unijuí, 2011.

NASCIMENTO, Cláudia Terra do; BRANCHER, Vantoir Roberto; OLIVEIRA, Valeska Fortes de. A construção social do conceito de infância: uma tentativa de reconstrução historiográfica. Linhas, Florianópolis, v. 9, p. 4-18, jan./jun. 2008.

NóVOA, António. Os professores na virada do milênio: do excesso dos discursos à pobreza das práticas. Palestra. Faculdade de Educação, Universidade de São Paulo, São Paulo, Brasil, 20 de maio 1999.

OLIVEIRA, Zilma Moraes Ramos de (org.). Educação infantil: muitos olhares. 9. ed. São Paulo: Cortez, 2010.

PENHA, Ana Cristina Gomes da. Inovações educativas no cotidiano escolar. Currículo, educação infantil, Ensino Fundamental, Ensino Médio e avaliação. COLÓQUIO SOBRE QUESTÕES CURRICULARES, 12., COLÓQUIO LUSO-BRASILEIRO DE CURRÍCULO, 8., e COLÓQUIO LUSO-AFRO-BRASILEIRO DE QUESTÕES CURRICULARES, 2., 2016, Recife. Série Anais [...]. Recife, Pernambuco, 2016.

SANTOS, Vera Lúcia Bertoni dos. Promovendo o Desenvolvimento do faz-de-conta na educação infantil. In: CRAIDY, Carmem Maria; KAERCHER, Gládis Elise P. da Silva (org.). Educação infantil: pra que te quero? Porto Alegre: Artmed, 2001.

SALLES, Fátima; FARIA, Vitória Líbia Barreto de. Currículo na educação infantil: diálogo com os demais elementos da Proposta Pedagógica. 2. ed. São Paulo: Ática, 2012.

TOKUHAMA-ESPINOSA, Tracey Noel. The scientifically substantiated art of teaching: a study in the develop- ment of standards in the new academic field of neuroeducation (mind, brain, and education science). 2008. Tese (Doutorado) - Capella University, Programa de Pós-Graduação em Educação, Mineápolis, Minesota, 2008.

VASCONCELLOS, Celso dos Santos. Coordenação do trabalho pedagógico: do projeto político-pedagógico ao cotidiano da sala de aula. São Paulo: Libertad, 2006.

VASCONCELLOS, Celso dos Santos. Metodologia dialética em sala de aula. Revista de Educação AEC, Brasília, n. 83, abr. 1992.

VIGOTSKII, Lev Semenovich. Aprendizagem e desenvolvimento intelectual na idade escolar. In: VIGOTSKII, Lev Semenovich; LURIA, Alexander Romanovich; LEONTIEV, Alex N. Linguagem, desenvolvimento e aprendizagem. Tradução Maria da Penna Villalobos. 11. ed. São Paulo: Ícone, 2010.

ZARO, Milton Antonio; ROSAT, Renata Menezes; MEIRELES, Luis Otoni Ribeiro; SPINDOLA Marilda; AZEVEDO, Maria Ponzio de; BONINI-ROCHA, Ana Clara; TIMM, Maria Isabel. Emergência da Neuroeducação: a hora e a vez da neurociência para agregar valor à pesquisa educacional. Porto Alegre: UFRGS, 2010. Ciências \& Cognição, v. 15, n. 2, p. 199-210. Disponível em: http://www.cienciasecognicao.org. Acesso em: 21 jul. 2016. 